\title{
O DIREITO COMO SISTEMA: DEVER DE COERÊNCIA E AS ANTINOMIAS SEGUNDO NORBERTO BOBBIO
}

\author{
LAW AS A SYSTEM: DUTY OF COHERENCE AND ANTINOMIES ACCORDING NORBERTO BOBBIO
}

\section{Franciele Silva Cardoso*}

\begin{abstract}
Resumo:
A teoria do ordenamento jurídico de Norberto Bobbio baseia-se nos pilares da unidade, coerência e completude. A coerência é um traço que, complementado por outros, caracteriza o sistema. O ordenamento jurídico pode ser considerado um sistema jurídico. Na solução das antinomias, a adoção de critérios o mais objetivo quanto possível é um imperativo de justiça.

Palavras-chave: Sistema. Ordenamento jurídico. Coerência. Antinomias. Critérios de solução de antinomias jurídicas. Justiça.
\end{abstract}

\begin{abstract}
:
The Norberto Bobbio's theory of the law is based on the pillars of unity, consistency and completeness. Consistency is a trait, complemented by other, that characterizes legal systems. Legal ordinance is considered a legal system. In the solution of the antinomies, the adoption of criteria as objective as possible is an imperative of justice.
\end{abstract}

Keywords: The system. Legal. Consistency. Antinomies. Solution criteria for antinomies. Justice.

Introdução

Na vasta obra de Norberto Bobbio, o seu amadurecimento em relação a categorias jurídicas basilares é inegável. Em relação à teoria do Direito, e especificamente à sua aproximação com o positivismo jurídico, com Santi Romano ${ }^{1}$ num primeiro momento, mas principalmente com a obra de Hans Kelsen ${ }^{2}$ posteriormente, pode-se visualizar com

* $\quad$ Professora Assistente da Faculdade de Direito da Universidade Federal de Goiás, advogada e doutoranda em Direito Penal e Criminologia na Faculdade de Direito da Universidade de São Paulo, sob a orientação do Professor Titular Sérgio Salomão Shecaira.

1 Norberto Bobbio fez questão de deixar consignada a trajetória de sua aproximação do positivisno jurídico e, principalmente, a sua reflexão jusfilosófica sobre esta corrente. Veja-se, por exemplo, os esclarecimentos do próprio autor em O positivismo jurídico: lições de filosofia do Direito, p. 197-198; e ainda na Teoria do Ordenamento Jurídico, p. 20-21.

2 A influência de Hans Kelsen na obra de Norberto Bobbio é inegável. Como anteriormente afirmado, o próprio Bobbio, a todo momento, a ela se refere, ocasião em que se somam as suas sinceras homenagens e deferência ao grande jurista austríaco. Porém não menos segura é a constatação de que Bobbio foi além da teoria Kelsniana, adotando-a como premissa mas dela se distanciando em vários aspectos, como nos noticiou o jusfilósofo do Recife Nelson Saldanha em uma comunicação ao V Congresso Brasileiro de Filosofia do Direito, realizado em Goiânia em setembro de 1992 e depois incluída com o sugestivo título 
toda a clareza a riqueza de sua análise, a argúcia de sua reflexão e, principalmente, a pertinência de sua formulação de uma Teoria do Direito própria: num primeiro momento calcada no estudo da norma e, posteriormente, na exploração do conjunto delas e suas especificidades: o Ordenamento Jurídico.

Sobre a obra filosófica de Bobbio, Celso Lafer, afirma que

a sua filosofia do Direito é a de um jurista que parou para pensar os problemas concretos colocados pela experiência jurídica, as suas respostas precisas e rigorosas são relevantes e se tornaram um indispensável ponto de referência para o mundo jurídico brasileiro (LAFER, 2004, p. 128).

Nessa perspectiva jusfilosófica, construindo sua obra calcada no profundo respeito ao rigor metodológico e de linguagem, é que foi formulada por Bobbio a sua Teoria do Ordenamento Jurídico, posteriormente e em complementação analítica à sua Teoria da Norma Jurídica, constituindo, como o próprio autor esclarece "uma integração da teoria da norma jurídica" (BOBBIO, 1995, p. 22).

Por conta do recorte imprescindível ao trabalho acadêmico e com vistas a delimitar melhor o objeto de análise, o presente artigo tratará, de forma deliberadamente pedagógica, da teoria bobbiana do ordenamento jurídico, precisamente sobre a importância da noção de sistema subjacente a esta teoria.

Será contemplado ainda mais detidamente o tratamento dado por Bobbio ao imperativo da coerência do ordenamento jurídico, especificamente em relação às suas proposições para a solução das antinomias nele presentes. Acerca dos critérios de solução de antinomias, tratar-se-á desde a formulação original da teoria do ordenamento, que foi apresentada pela primeira vez em seu curso na Universidade de Turim nos anos de 1957 $58^{3}$, até o seu apogeu, quando publicou, em 1970, o seu Studi per uma teoria generale del Diritto, onde dedicou um capítulo especial ao problema das antinomias, denominado sui criteri per risolvere le antinomie.

1. Primeira ancoragem: a noção de sistema

Ao formular sua teoria do ordenamento jurídico, Bobbio afirma que os problemas principais a serem enfrentados são as questões da unidade - saber se as inúmeras normas jurídicas que compõem um ordenamento constituem uma unidade -, da sistematicidade - saber se o ordenamento jurídico constitui, além de uma unidade, também um sistema, e por conta deste "desafio" é que o autor se debruçará sobre o problema das

\footnotetext{
“A filosofia do Direito na transição do milênio" na sua obra Estudos de teoria do Direito (p. 129-137), publicada pela Del Rey em 1994.

3 Conforme esclarecimentos do próprio Norberto Bobbio apresentados em sua obra, traduzida no Brasil com o título Direito e Poder, editada em São Paulo em 2006 pela editora Unesp, p. 12.
} 
antinomias jurídicas - e, por último da completude - saber se todo ordenamento jurídico, unitário e tendencialmente sistemático, também pode ser completo (BOBBIO, 1995, p. 34-35).

A partir do já mencionado recorte temático aqui empreendido, será enfatizada a segunda questão enfrentada por Bobbio na formulação da sua teoria do ordenamento jurídico: o caráter (ou tendência) sistemático do mesmo. Para tanto, analisemos, ainda que brevemente, a noção de sistema e a sua apropriação pelos juristas.

1.1. A ideia de sistema

Celso Lafer observa, sobre a apropriação do conceito de sistema pelo Direito, que:

\begin{abstract}
A idéia de sistema constitui um aspecto fundamental da contribuição do Direito Natural à jurisprudência européia, que deixou de limitar-se à exegese e à interpretação prudencial de textos singulares e passou a ter características de uma estrutura lógico-demonstrativa. Ora, transposta e positivada pelos códigos e pelas constituições a visão jusnaturalista de um Direito racional e sistemático, foi perdendo significado a idéia de outro Direito que não o Direito do Código e da Constituição. Por isso, o fundamento do Direito deixou de ser buscado nos ditames da razão e passou a afirmar-se como a vontade do legislador, independentemente de qualquer juízo sobre a conformidade desta vontade com a razão. Nesse sentido, o processo de laicização e sistematização do Direito terminou por confluir com o fenômeno da crescente positivação do Direito pelo Estado, que é outro processo característico no mundo moderno (LAFER, 1988, p. 39).
\end{abstract}

Realmente, a ascensão do positivismo jurídico levou ao entendimento quase automático de que um dado conjunto de regras jurídicas se caracteriza como um "sistema jurídico": veja-se, por exemplo, o conceito de José Afonso da Silva: "O Direito é fenômeno histórico-cultural, realidade ordenada, ou ordenação normativa da conduta segundo uma conexão de sentido. Consiste num sistema normativo" (AFONSO DA SILVA, 2004, p. 33).

Também dentre insignes juristas internacionais, a conceituação do Direito como sistema de maneira quase apriorística se repete. O conceito de Hans Kelsen segue esta linha: “o Direito é uma ordem normativa da conduta humana, ou seja, um sistema de normas que regulam o comportamento humano" (KELSEN, 1985, p. 4) (grifo nosso). Mais recentemente, Manuel Calvo Garcia foi categórico ao afirmar "El Derecho es uno de los sistemas normativos sociales y cualquier aproximación al concepto de derecho debe partir de este dato." (CALVO GARCÍA, 2002, p. 50) 
Porém, analisar a função da ideia de sistema na ciência do Direito pressupõe uma aproximação do seu conceito geral ou filosófico e, somente a partir daí avaliar a repercussão e utilidade jurídica do mesmo. Esta tarefa, entretanto, é das mais complexas, como nos adverte Claus-Wilhelm Canaris, para quem

A questão do significado da idéia de sistema para a Ciência do Direito é dos temas mais discutidos da metodologia jurídica. Em poucas controvérsias estão, ainda hoje, as opiniões tão divididas. Enquanto, por exemplo, SAUER exclama com ênfase: "Apenas o sistema garante conhecimento, garante cultura. Apenas no sistema é possível verdadeiro conhecimento, verdadeiro saber" e H. J. WOLFF diz: "A ciência do Direito ou é sistemática ou não existe", EMGE opina, com discrição céptica: "Um sistema é sempre um empreendimento da razão com um conteúdo exagerado" uma afirmação que está apenas a curta distância da célebre frase de NIETZSCHE que caracterizou a aspiração ao sistema como uma "falta na consecução do Direito" e uma “doença no caráter” (CANARIS, 2002, p. 5).

A par das complexas discussões teóricas em torno do caráter sistemático do Direito, Miguel Reale, por sua vez, firma sua posição sobre o tema ao asseverar que

Com mais razão impõe-se reconhecer que as normas jurídicas, que são conceitos ou modelos ético-funcionais da experiência jurídica, não são objetos catalogáveis segundo um saber tópico ou aporético, que se baste a si próprio, porque cada uma delas, e, mais ainda, - como veremos melhor nos Ensaios dedicados ao problema da Hermenêutica jurídica, - a interpretação de cada uma delas implica a totalidade do ordenamento, numa unidade objetiva e sistemática de significados (REALE, 1992, p. 139) (grifo nosso).

Ressalte-se que, para o objetivo do presente trabalho, optou-se deliberadamente por apenas referir tal discussão metodológica, ${ }^{4}$ e adotar, pela sua precisão, a definição que Tércio Sampaio Ferraz Júnior nos dá de sistema, nos seguintes termos:

Entendemos por sistema um conjunto de objetos e seus atributos (repertório do sistema), mais as relações entre eles, conforme certas regras (estrutura do sistema). Os objetos são os componentes do sistema, especificados pelos seus atributos, e as relações dão o sentido de coesão ao sistema. (FERRAZ JR., 2002, p. 140).

A opção aqui adotada justifica-se, também, pelo fato de ser a partir desta mesma linha de raciocínio e partindo da mesma perspectiva - a ênfase nas relações

\footnotetext{
4 Indica-se para um estudo aprofundado do conceito de sistema e sua utilização na Ciência do Direito, a própria obra de Claus-Wilhelm Canaris, citada no corpo do texto, além de Sistema e estrutura no Direito, especialmente o volume 1, de Mário G. Losano e Conceito de sistema no Direito: uma investigação histórica a partir da obra jusfilosófica de Emil Lask, de Tércio Sampaio Ferraz Júnior.
} 
estabelecidas no âmbito do repertório do sistema -, que Bobbio construirá a sua Teoria do Ordenamento Jurídico, conforme se verá adiante.

1.2. O ordenamento jurídico na visão bobbiana: um sistema coerente

Para Bobbio, conforme já mencionado, Ordenamento Jurídico é um conjunto unitário, sistemático (coerente) e completo.

Após tratar da questão da unidade, Norberto Bobbio passa a questionar se o ordenamento jurídico também constituiria um sistema. Para tanto, o autor inicia sua análise utilizando-se de aproximações sucessivas, considerando sistema uma totalidade ordenada, isto é, o conjunto de entes entre os quais existe uma certa ordem. E haverá ordem, para Bobbio, quando esses entes estiverem em relacionamento com o todo e também em relacionamento de coerência entre si. Neste sentido, saber se um ordenamento é um sistema equivale saber se as normas estão em coerência entre si e em que condições é possível essa relação.

Já Tércio Sampaio Ferraz Júnior, ao tratar da dogmática analítica, acrescenta que

ordenamento é um conceito operacional que permite a integração das normas num conjunto, dentro do qual é possível identificá-las como normas jurídicas válidas. Concretamente, seu repertório não contém apenas elementos normativos, mas como vimos, também não normativos. A decisão de incluí-los ou não na consideração do ordenamento como sistema é uma opção teórica cujo fundamento último é um problema zetético. (FERRAZ JR., 2001, p. 173).

Por sua vez, Bobbio utiliza-se da distinção kelseniana entre sistema estático e sistema dinâmico para construir sua própria noção de sistema. Assim, segundo Kelsen, em um sistema estático as normas se relacionam entre si como proposições de um sistema dedutivo - normas derivam umas das outras, a partir de normas originárias de caráter geral. Aqui as normas estão relacionadas entre si relativamente ao seu conteúdo. Por seu turno, em um sistema dinâmico, as normas que o compõem derivam umas das outras através de sucessivas delegações de poder - uma norma, emanada por uma autoridade inferior, deriva de uma norma superior, emanada por uma autoridade superior, até chegarse a uma autoridade suprema. Aqui as normas estão relacionadas formalmente.

Segundo Bobbio, a definição de Kelsen sobre sistema dinâmico não seria completa, pois seria possível admitir, em um mesmo sistema, duas normas em oposição como perfeitamente legítimas, desde que emanadas pelas autoridades competentes. É a partir de tal constatação que o jurista de Turim passa então a trabalhar um conceito próprio de sistema jurídico. 
Neste passo, o autor propõe três significados básicos para sistema (BOBBIO, 1995, p. 75-81), quais sejam: sistema como conjunto em que as normas jurídicas derivam todas de alguns princípios gerais - são como os postulados de um sistema científico. É a acepção utilizada por jusnaturalistas modernos e racionalistas ao organizar o direito como um sistema dedutivo.

Num segundo significado, sistema seria um ordenamento da matéria, realizado de forma indutiva. A partir do conteúdo das normas simples constroem-se conceitos mais gerais, com classificações ou divisões da matéria inteira. A consequência desta atividade organizativa será o próprio ordenamento jurídico. Exemplo da adoção desse segundo significado nos é dado pela Escola da "jurisprudência sistemática" ou pandectista alemã.

E, finalmente, Bobbio apresenta o terceiro significado de sistema como um ordenamento no qual não coexistem normas incompatíveis. As normas têm relacionamento de compatibilidade entre si, devendo ser excluída a incompatibilidade. Mas aqui não se pretende um sistema coerente no todo, mas a coerência deve ser pensada como exigência entre as partes simples do sistema. Em suas palavras:

Num sistema dedutivo, se aparecer uma contradição, todo o sistema ruirá. Num sistema jurídico, a admissão do princípio que exclui a incompatibilidade tem por conseqüência, em caso de incompatibilidade de duas normas, não mais a queda de todo o sistema, mas somente de uma das duas normas ou no máximo das duas (BOBBIO, 1995, p. 80).

Em relação ao sistema dedutivo, o sistema jurídico seria algo de menos. Em relação ao sistema dinâmico, seria algo a mais, pois não trata somente da relação formal entre as normas, mas também inclui a verificação da compatibilidade entre elas. Assim, para esta terceira concepção de sistema, a norma será válida não apenas porque foi emitida por autoridade competente, mas também porque é compatível com outras normas. Bobbio adota essa terceira concepção de sistema e passa a trabalhar a questão das antinomias.

2. As antinomias jurídicas na formulação original da Teoria do Ordenamento Jurídico

Norberto Bobbio aborda o problema das antinomias explicitando-as como conflitos dos modais deônticos: obrigatório, proibido, permitido negativo, permitido positivo. A partir das correlações possíveis entre os mesmos, ele aponta quais seriam as antinomias normativas efetivas, asseverando que as relações de incompatibilidade normativa verificam-se em três casos: (i) entre uma norma que ordena fazer algo e uma norma que proíbe fazê-lo (contrariedade); (ii) entre uma norma que ordena fazer e uma que permite não fazer (contraditoriedade) e (iii) entre uma norma que proíbe fazer e uma que permite fazer (contraditoriedade). 


\subsection{Conceito de Antinomia}

Assim, a antinomia jurídica seria o conflito entre duas normas incompatíveis, pertencentes ao mesmo ordenamento e tendo o mesmo âmbito de validade temporal, espacial, pessoal e/ou material (BOBBIO, 1995, p. 88). O Autor aponta três tipos diferentes de antinomia, conforme a maior ou menor extensão do contraste entre as duas normas:

Em primeiro lugar, se as duas normas incompatíveis têm igual âmbito de validade, a antinomia é denominada total-total: em nenhum caso uma das duas normas pode ser aplicada sem entrar em conflito com a outra; em segundo lugar, a antinomia ocorre se as duas normas incompatíveis têm âmbito de validade em parte igual e em parte diferente, a antinomia subsiste apenas para a parte comum, e pode chamar-se parcialparcial; e, por último, se, de duas normas incompatíveis, uma tem um âmbito de validade igual ao da outra, porém mais restrito, ou, em outras palavras, se o âmbito de validade é, na íntegra, igual a uma parte do da outra, a antinomia é total por parte da primeira norma com respeito à segunda, e somente parcial por parte da segunda com respeito à primeira, e pode chamar total-parcial.

Bobbio ainda aponta a existência das chamadas antinomias impróprias, as quais envolveriam antinomias de princípios, de avaliação e antinomias teleológicas. Essas antinomias não poderiam ser consideradas propriamente antinomias, pois o conflito existente não se dá entre normas (BOBBIO, 1995, p. 90-91).

Para resolução de antinomias, o autor apresenta critérios desenvolvidos pela doutrina e elabora nova distinção entre antinomias solúveis (aparentes) e antinomias insolúveis (reais). Logo, as antinomias que podem ser resolvidas pelos critérios apresentados a seguir seriam as antinomias solúveis. Seriam antinomias reais somente aquelas que não se resolvem mediante a aplicação dos referidos critérios.

Neste passo, as regras fundamentais para a solução de antinomias seriam: (i) o critério cronológico (lex posterior): Lei posterior derroga lei anterior; (ii) o critério hierárquico (lex superior): Lei superior derroga lei inferior - Entre duas normas incompatíveis, das quais uma é consuetudinária, prevalece a legislativa, desde que nesse ordenamento dado, o costume seja inferior à lei (caso do Ordenamento Jurídico italiano) e (iii) o critério da especialidade (lex specialis): Lei especial derroga lei geral - Por efeito da lei especial, a lei geral cai parcialmente (é uma antinomia total-parcial).

Uma possibilidade de antinomia real, insolúvel, seria aquela envolvendo normas contemporâneas, de mesmo nível e ambas gerais. Segundo Bobbio, não haveria critério definido para resolução de tal tipo de antinomia. Em um primeiro momento, tentou-se estabelecer uma solução baseada nas diversas formas de normas jurídicas (imperativas, proibitivas e permissivas), sendo preferível, numa antinomia entre normas imperativas ou proibitivas e uma norma permissiva, aplicar-se a segunda, por ser ela, em geral, mais favorável. Mas, analisando-se com mais cuidado tal critério, percebe-se 
facilmente que ele padece de ambiguidade insolúvel, podendo levar à injustiça em função, principalmente, da bilateralidade da maior parte das relações jurídicas, o que leva Bobbio a afirmar a sua imprestabilidade, nos seguintes termos:

o problema real, frente ao qual se encontra o intérprete, não é o de fazer prevalecer a norma permissiva sobre a imperativa ou vice-versa, mas sim o de qual dos dois interesses em conflito é justo fazer prevalecer: mas nessa decisão a diferença formal entre as normas não lhe oferece a mínima ajuda (BOBBIO, 1995, p. 99).

Outra situação de antinomia descrita pelo autor, cujo critério poderia ser baseado na forma das normas, se dá entre uma norma imperativa e a outra proibitiva (normas contrárias), as quais se excluem, sim, uma a outra, mas não excluem uma terceira solução: no conflito entre obrigação positiva e obrigação negativa, o tertium é a permissão.

Bobbio afirma que os critérios deduzidos da forma da norma não teriam a mesma legitimidade dos três critérios principais de solução de antinomias (cronológico, hierárquico e da especialidade) e que a atividade do intérprete ganha ampla liberdade (seria quase um poder discricionário, a quem cabe resolver a antinomia segundo a oportunidade).

Nesse caso, o autor aponta três possibilidades: (i) eliminar uma norma interpretação ab-rogante imprópria simples, pois a oposição entre as duas normas é de contradição (inconciliáveis, portanto), cabendo ao intérprete eliminar uma delas, preservando-se a outra; (ii) eliminar as duas normas - interpretação ab-rogante imprópria dupla, pois a oposição entre as duas normas é de contrariedade, não de contradição e (iii) conservar as duas normas - interpretação corretiva, demonstrando-se que as normas em confronto não são essencialmente incompatíveis, mas apenas na aparência. Bobbio pondera ao final que, na verdade, a interpretação corretiva seria uma forma atenuada das duas formas de interpretação ab-rogante descritas anteriormente.

Finalmente, ainda na teoria do ordenamento jurídico, Norberto Bobbio trata da possibilidade de aplicação de dois ou mais critérios para resolução de antinomias. Tratar-se-ia, assim, de incompatibilidade ou antinomia de segundo grau, pois se fala aqui em incompatibilidade de critérios de solução de antinomias e não de normas.

Como já anteriormente tratado, sendo três os critérios para resolução de antinomias, $(\mathrm{A}, \mathrm{B}, \mathrm{C})$, os conflitos entre os mesmos podem ser três: A com B, B com C, A com C. Veja-se: (i) Conflito entre o critério hierárquico e o cronológico: ocorre quando uma norma anterior-superior é antinômica em relação a uma norma posteriorinferior $=>\mathbf{O}$ critério hierárquico prevalece sobre o cronológico; (ii) Conflito entre o critério de especialidade e o cronológico: ocorre quando uma norma anterior-especial é incompatível com uma norma posterior-geral $=>\mathbf{O}$ critério da especialidade prevalece sobre o cronológico, vale dizer, lei geral posterior não derroga lei especial anterior e (iii) Conflito entre o critério hierárquico e o de especialidade: Não existe uma regra geral 
consolidada, a solução dessa antinomia de segundo grau (entre critérios de solução de antinomias) vai depender do intérprete, aplicando-se um ou outro critério a cada caso.

Bobbio encerra esta parte de sua Teoria do Ordenamento Jurídico afirmando que a coerência não é condição de validade, mas é condição de justiça do ordenamento, uma vez que

onde existem duas normas antinômicas, ambas válidas, e portanto ambas aplicáveis, o ordenamento jurídico não consegue garantir nem a certeza, entendida como possibilidade, por parte do cidadão, de prever com exatidão as conseqüências jurídicas da própria conduta, nem a justiça, entendida como o igual tratamento das pessoas que pertencem à mesma categoria. (BOBBIO, 1995, p. 113).

2.2. Ainda a questão das antinomias jurídicas: a reaproximação bobbiana do tema na década de 70

Em obra posterior, intitulada Studi per uma teoria generale del diritto, Bobbio aprofundou suas considerações relacionadas a temática das antinomias - trata-se do artigo datado de 1970 chamado Sui criteri per risolvere le antinomie. Neste texto, o autor tratará com maior detalhe a questão relativa ao conflito de critérios para resolução de antinomias, as chamadas antinomias de segundo grau.

Bobbio inicia suas considerações distinguindo o "problema da verdade" e o "problema da justiça". O primeiro envolve critérios de verificação de uma afirmação - verificar se algo é verdadeiro ou falso leva a um resultado mais aceitável em relação a pesquisa desenvolvida. Já o segundo problema envolve critérios de justificação de uma norma - verificar se algo é justo ou injusto, segundo o mesmo autor, não levaria a resultados tão objetivos e aceitáveis.

Neste sentido, o jurista de Turim afirma que os critérios para resolução de antinomias não deveriam estar submetidos à avaliação pessoal do intérprete. Os critérios para resolução de antinomias estariam relacionados a fatos verificáveis, isentos de intervenção valorativa pessoal. Esses critérios seriam, assim, mais objetivos que um processo de justificação de uma norma. O processo de justificação leva a resultados mais incertos, menos verificáveis. Por conta da necessidade de certeza no direito, critérios que deixam margem para valoração deveriam ser substituídos, quando possível, por critérios objetivos (BOBBIO, 1970, p. 98-99).

$\mathrm{O}$ autor dá continuidade a sua análise afirmando que os três critérios para resolução de antinomias funcionariam como uma presunção - podem valer inclusive para casos futuros ainda não observáveis. A partir de fatos conhecidos (data das normas, fontes hierarquicamente dispostas, maior ou menor extensão material ou pessoal), revelam-se determinados valores. Logo, ao invés de adentrar pelo caminho longo da justificação 
(norma justa versus norma injusta), trabalha-se com fatos conhecidos e verificáveis. No entanto, esses critérios se referem a fatos verificáveis aos quais atribuímos a qualidade de revelar uma transformação na valoração do que é justo ou injusto. Trata-se, portanto, de presunções de justiça.

Norberto Bobbio entende justiça aqui no sentido amplo, como critério último para valoração de uma norma. Assim, a norma posterior seria MAIS JUSTA do que a norma anterior e as normas superiores e especiais seriam MAIS JUSTAS do que aquelas inferiores e gerais (BOBBIO, 1970, p. 104).

$\mathrm{Na}$ medida em que Bobbio passa a analisar diversas situações de conflitos entre critérios para resolução de antinomias, evidencia a dificuldade em se manter o caráter totalmente objetivo desses critérios. Há situações em que se faz necessário o apelo à valoração do intérprete, à sua consideração sobre a justiça da aplicabilidade de determinado critério em detrimento de outro para resolução de uma antinomia de segundo grau.

De forma bastante resumida, Bobbio conclui que, em face do critério hierárquico, o critério de especialidade se comporta da mesma forma como se comporta em relação ao critério cronológico: o critério de especialidade prevalecerá a depender da interpretação dada à norma especial. Se a norma especial for vista como mais justa, ela deverá prevalecer. Enquanto o critério cronológico seria sempre mais fraco em relação ao critério hierárquico, o critério de especialidade pode ser tanto mais forte quanto mais fraco em relação aos critérios hierárquico/cronológico (BOBBIO, 1970, p. 116).

Desta feita, a resolução de antinomias de segundo grau que envolvam o critério de especialidade não é automática e totalmente objetiva. Bobbio pondera que essa resolução dependerá de uma interpretação que não se apoia em nenhuma presunção, mas estará baseada na busca pela justiça - na regra que prega tratar os iguais de forma igual e os diferentes de forma diferente.

Bobbio conclui neste texto que, em situações mais extremas, em que falta um critério para resolver o conflito de critérios, o critério último seria sempre aquele da justiça. Esse texto de 1970 denota uma ulterior reflexão de Bobbio se considerarmos a "Teoria do Ordenamento Jurídico", restando claro nesse momento a sua passagem da estrutura à função. ${ }^{5}$

\footnotetext{
$5 \quad$ No Brasil, os escritos de Norberto Bobbio que demonstram essa mudança de paradigma - da estrutura para uma análise funcional do Direito estão reunidos prioritariamente na coletânea intitulada Da estrutura à função: novos estudos de teoria do direito, publicada pela Editora Manole em 2007.
} 
Conclusão

A mera tentativa de aproximação da obra de Norberto Bobbio revela-se, desde o início, fascinante. Trata-se de alguém que, muito mais que um jusfilósofo, foi um pensador dos problemas do seu tempo e, ainda mais raro, um fervoroso e incansável combatente no périplo da sua solução. Com a mesma competência e rigor científico, tratou tanto dos mais diversos temas da filosofia e do direito, quanto da política. Foi, assim, um militante raro, pois mais que um defensor de uma ideologia ou causa, mero reprodutor de teorias prontas, foi ele mesmo um formulador e crítico de correntes ou pretensas "escolas" de pensamento ou de ações políticas. ${ }^{6}$

O mais surpreendente na trajetória deste importante pensador é, a par de tamanha erudição, a clareza da sua escrita, a limpidez do seu raciocínio e a extrema habilidade em se fazer entender. Por isso, a leitura de sua obra é tão fluida e, sempre, tão necessária.

Tratou-se aqui de uma ínfima parcela do enorme acervo de temas que foram trabalhados, ao longo de toda uma vida de dedicação à Academia, pelo consagrado jusfilósofo de Turim. Os objetivos eram, diante dos sucessivos recortes empreendidos para a delimitação do objeto de análise, modestos. Porém, a aproximação com as proposições bobbianas em torno da noção de sistema e o consequente imperativo de sua coerência e, nesta perspectiva, o tratamento que se deve dar às antinomias imanentes ao Ordenamento Jurídico revelou-se de grande utilidade para a compreensão dos complexos dilemas cotidianamente vivenciados pelos intérpretes ao manejá-lo para extrair o sentido das mais diversas normas que o compõe.

É inspirador verificar que a inquietação de Norberto Bobbio em torno de temas que foram por ele constantemente revisitados a fim de, após detida reflexão, lapidá-los teoricamente, tinha como objetivo, sempre, a busca pelo ideal de justiça. E é justamente esta grande qualidade deste pensador que buscamos ressaltar ao tratar da sua Teoria do Ordenamento Jurídico, especificamente no que tange à sua sistematicidade e o enfrentamento do problema das antinomias, indispensável para a garantia da coerência sistêmica.

Finalmente, esperamos que a tarefa de formular, não uma análise exaustiva - e absolutamente impossível em tão limitado espaço da contribuição de Bobbio para a melhor compreensão do Direito - mas, principalmente, um convite ao estudioso do

$6 \quad$ Este viés da obra (e da práxis) de Norberto Bobbio pode ser apreciada, dentre tantos outros, no livro por ele organizado, com a colaboração de outros experts da matéria, intitulado O marxismo e o Estado, publicado no Brasil pela Editora Graal pela primeira vez em 1979, mas com várias edições posteriores. Nesta coletânea de artigos, há três preciosos escritos de Bobbio sobre a eventual existência de uma "teoria marxista do Estado", a democracia e, ainda mais instigante, um terceiro sobre o socialismo, onde responde aos seus interlocutores e parceiros na publicação com uma lucidez raramente vista. É mais um momento de absoluta maturidade intelectual e política, tão característicos do mestre de Turim. 
Direito a rever ${ }^{7}$ este grande autor tenha sido pelo menos parcialmente alcançada. É o mínimo que um pensador de tão elevada envergadura merece dos seus leitores brasileiros no ano em que, com toda a pertinência, celebramos o centenário do seu nascimento.

São Paulo, janeiro de 2012.

\section{Referências}

AFONSO DA SILVA, José. Curso de direito constitucional positivo. 23. ed., rev e atual. São Paulo: Malheiros Editores, 2004.

BOBBIO, Norberto. A teoria do ordenamento jurídico. In: O positivismo jurídico: lições de filosofia do direito. São Paulo: Editora Ícone, 1995.

. Da estrutura à função: novos estudos de teoria do direito. Tradução de Daniela Beccaccia Visiani; revisão técnica de Orlando Seixas Bechara, São Paulo: Manole, 2007.

. et. al. O Marxismo e o Estado. Trad. De Frederica L. Boccardo e Renée Levie. Rio de Janeiro: Edições Graal, 1979.

Sui criteri per risolvere le antinomie. In: Studi per una teoria generale del diritto. Torino: Edizioni Giappichelli, 1970.

. Teoria do ordenamento jurídico. 6. ed. Brasília: Editora UNB, 1995.

CALVO GARCÍA, Manuel. Teoria del derecho. 2. ed., rev. e aum. Madrid: Editorial Tecnos, 2002.

CANARIS, Claus-Wilhelm. Pensamento sistemático e conceito de sistema na ciência do Direito. Int. e trad. de A. Menezes Cordeiro. 3. ed. Lisboa: Ed da Fundação Calouste Gulbenkian, 2002.

FERRAZ JÚNIOR, Tércio Sampaio. Conceito de sistema no direito: uma investigação histórica a partir da obra jusfilosófica de Emil Lask. São Paulo: Ed. Revista dos Tribunais, Ed. Da Universidade de São Paulo, 1976.

. Introdução ao estudo do direito: técnica, decisão, dominação. 3. ed. São Paulo: Atlas, 2001.

. Teoria da norma jurídica: ensaio de pragmática da comunicação normativa. 4. ed. Rio de Janeiro: Forense, 2002.

\footnotetext{
7 É deliberada a intenção do chamamento para um "reencontro" com Bobbio, uma vez que partimos da conviç̧ão, desde muito afirmada por Miguel Reale, Tércio Sampaio Ferraz Júnior, Celso Lafer, dentre tantos outros de que nós brasileiros temos, felizmente, largo contato com a extensa produção intelectual bobbiana, conforme se verifica nos inúmeros escritos aqui publicados pelos citados juristas brasileiros e tantos outros após a vinda de Bobbio ao Brasil em 1982, para um memorável encontro promovido pela Universidade de Brasília. Assim, o diálogo travado entre os maiores pensadores do Direito no Brasil dentre os quais destaca-se Miguel Reale - foi constante, e muito rico: não foi, absolutamente, baseado somente em concordâncias (vide, por exemplo, as críticas de Miguel Reale às posições neo-positivistas de Bobbio publicadas em sua já citada obra $O$ Direito como experiência - p. 98-99). Cabe-nos agora, revisitálo com entusiasmo.
} 
KELSEN, Hans. Teoria pura do direito. São Paulo: Martins Fontes, 1985.

LAFER, Celso e FILIPPI, Alberto. A presença de Bobbio no Brasil. In: A presença de Bobbio: América espanhola, Brasil, Península ibérica. São Paulo: Ed. UNESP, 2004.

. A reconstrução dos Direitos Humanos: um diálogo com o pensamento de Hannah Arendt.

São Paulo: Companhia das letras, 1988.

LOSANO, Mario. Prefácio. In: BOBBIO, Norberto. Da estrutura à função. São Paulo: Editora Manole, 2007.

REALE, Miguel. O direito como experiência. 2. ed. São Paulo: Saraiva, 1992.

SALDANHA, Nelson. Estudos de teoria do direito. Belo Horizonte: Del Rey, 1994. 